Dimitri Létourneau*, Johanne Goudreau and Chantal Cara

\title{
Facilitating and hindering experiences to the development of humanistic caring in the academic and clinical settings: an interpretive phenomenological study with nursing students and nurses
}

https://doi.org/10.1515/ijnes-2019-0036

Received March 28, 2019; accepted July 10, 2020; published online xxx

\begin{abstract}
Objectives: This paper reports on nursing students' and nurses' lived experiences mediating their development of humanistic caring.

Methods: Using interpretive phenomenology, 26 participants were individually interviewed. A five-stage phenomenological analysis based on Benner's (Benner, P. (1994). Interpretive phenomenology: Embodiment, caring, and ethics in health and illness. Thousand Oaks, CA: SAGE) method occurred simultaneously.

Results: The analysis highlighted that the development of humanistic caring is affected by role models and counterexamples, environments in which humanistic caring is exalted or trivialized, communication-related courses, patient storytelling, and work overload.
\end{abstract}

Conclusions: It might be valuable to raise the awareness of nurse educators about their opportunity in shaping the development of students' humanistic caring.

Keywords: caring; competency; facilitating and hindering experiences; humanism; nursing education; phenomenology.

A glimpse into the multitude of international nursing practice standards reveals that nurses are expected to be caring practitioners (American Nurses Association, 2015). Several studies conducted in various care settings also suggest that patients look for and value this vital dimension of nursing (Delmas, O'Reilly, Iglesias, Cara, \& Burnier, 2016; Dewar \& Nolan, 2013; Haugan, Innstrand, \& Moksnes, 2013; Wiechula et al., 2016). Nursing research repeatedly demonstrated over the past 20 years that the more humanistic the nurses are, the more patients are likely to be satisfied about nursing care (Dingman, Williams, Fosbinder, \& Warnick, 1999; Larson, 2004; McClelland, Gabriel, \& DePuccio, 2018; Palese et al., 2011). Moreover, caring results in positive outcomes on patients' physical and mental well-being such as improved mental health (Tektaş \& Çam, 2017), enhanced well-being and resiliency (O’Reilly, Cara, Avoine, \& Brousseau, 2011), feeling of security (St-Germain, Blais, \& Cara, 2008), and increased motivation (van der Cingel, 2011).

Embodying humanism in contemporary nursing practice may, however, be a challenge (Létourneau, Cara, \& Goudreau, 2016). The nursing literature documents dehumanizing breakdowns such as scarce interactions between patients and nurses (Karlsson, Bergbom, von Post, \& Berg-Nordenberg, 2004), objectification, and care disconnected from patients' priorities and concerns (Avoine, 2012; Wolf, 2012). Several studies depicted

*Corresponding author: Dimitri Létourneau, Faculty of Nursing, Université de Montréal, Montreal, Quebec, Canada, E-mail: dimitri.letourneau-aspirot@umontreal.ca. https://orcid.org/0000-0001-5174-4024

Johanne Goudreau and Chantal Cara: Faculty of Nursing, Université de Montréal, Montreal, Quebec, Canada 
the consequences of these practices on patients: discouragement (Halldórsdóttir \& Karlsdóttir, 1996), feeling of being of little or no importance (Karlsson et al., 2004), suffering (Berglund, Westin, Svanström, \& Sundler, 2012), feeling alienated (Svanström, Sundler, Berglund, \& Westin, 2013), distrust (Halldórsdóttir, 2008), feeling humiliated (Eliasson, Kainz, \& von Post, 2008), or slowing down patients' rehabilitation process (Avoine, 2012).

Even though these dehumanizing practices may be deliberate at times (Avoine, 2012), nursing students are generally encouraged, through activities in their curricula, to encompass notions pertaining to humanism and caring (Adam \& Taylor, 2014). Yet, some evidence indicates a decline or an erosion of students' caring practices while they study nursing (Ma, Li, Zhu, Bai, \& Song, 2013; Wolf, Byrne, \& Hanson-Zalot, 2018) and after their graduation (Pearcey, 2010). Though these papers offer some answers explaining this phenomenon, rare are the studies exploring the experiences that facilitate and hinder the development of humanistic caring.

The aim of this paper is to report on nursing students' and nurses' lived experiences that facilitate and hinder the development of humanistic caring. These phenomenological results are part of a larger study whose purpose was to develop a cognitive learning model (Goudreau, Boyer, \& Létourneau, 2014; Tardif, 2006) of the humanistic caring competency, which is reported in another publication (Létourneau, Goudreau, \& Cara, 2020).

\section{Background}

On one of the highest levels of abstraction (Smith \& Liehr, 2014), humanism is regarded as a philosophy rooted in the intellectual movements of the Renaissance and the Enlightenment (Copson \& Grayling, 2015; Davies, 2008; Mazzocco, 2006). Generally speaking, humanism has been actualized in various perspectives that believed in the potential and dignity of human beings, honoring their freedom and capacity to shape their own destiny from the choices they make throughout their life (Lamont, 1997). These tenets were then reintroduced in the rise of humanistic psychology (Rogers, 1961, 1995/2012) and the relational thoughts of philosophers such as Mayeroff (1971/1990) and Buber (1970/1996).

In nursing, several North American theorists were inspired by at least one of the last three thinkers, renewing these humanistic underpinnings in the context of caring (Létourneau, Cara, \& Goudreau, 2017). In the current paper, caring is considered an approach grounded in humanism that shapes nursing care (Cara et al., 2016). The term "approach" wishes to reflect how humanistic caring is a way of being in relationships that can be witnessed in subtle attitudes (Cara et al., 2016). Originating from the nurse's consciousness, humanistic caring requires an authentic commitment to establish links of reciprocity with patients in order to heighten their human potential, promote their health and healing while preserving their human dignity (Létourneau et al., 2017). It is presumed that both the nurse's and the patient's human growth may mutually blossom as a result of humanistic caring (Cara et al., 2016; Létourneau et al., 2017).

A recent meta-synthesis (Logan, 2017) highlighted the paucity of research about caring in nursing education between the years 2000-2015, yet, there are some experiences that might enhance students' development of humanistic caring. For instance, several studies discovered that the positive relationships between educators and students could inspire them to become caring practitioners (Adam \& Taylor, 2014; Bray, O'Brien, Kirton, Zubairu, \& Christiansen, 2014; Mikkonen, Kyngäs, \& Kääriäinen, 2015). Conversely, humanistic or caring frameworks (Hills \& Watson, 2011) used in curriculum or work environments, were found to foster humanistic caring for nursing students (Cara, 2001; Krol, 2010; Lee-Hsieh, Kuo, Turton, Hsu, \& Chu, 2007; Raines, 2007) and nurses (Boykin, Schoenhofer, \& Aleman, 2003; Dewar \& Cook, 2014).

The most documented hindering experience to the development of humanistic caring, both for students and nurses, appear to be related to the culture of the clinical field itself (Cornwell, Donaldson, \& Smith, 2014). The studies of Maben, Latter, and Clark (2007), Brown, Nolan, and Davies (2008), as well as Curtis, Horton, and Smith (2012) outlined that students felt disenchanted by incongruent paradigms such as those that are pathologically or productivity-centered. Nurses who participated in a phenomenological study (Rytterstöm, Cedersund, \& Arman, 2009) voiced that a routine-oriented culture of care distanced them from being caring 
practitioners. Finally, some nurses and physicians themselves discouraged or reprimanded other nurses when they felt they were merely speaking too much with patients, undermining, and devaluing relational nursing care (Beagan \& Ells, 2007; Gray, 2009).

\section{Method}

Interpretive phenomenology (Benner, 1994) was the methodological approach chosen in this study. Phenomenology is both 1) a philosophy (Spiegelberg \& Schuhmann, 1994) mainly rooted in the writings of Husserl (1913/1950) and Heidegger (1927/2008) and, 2) a qualitative research method (Munhall, 2012). For instance, Benner's phenomenological (1994) method stems from the Heideggerian school of thought (Heidegger, 1927/ 2008), hence it gives paramount importance to the understanding and interpretation of human existence, the Dasein. Benner (1994) brought forward that phenomenology could be a relevant methodological approach to uncover the taken-for-granted of nursing practice and to interpret the "ready-to-hand" mode of involvement (Heidegger, 1927/2008) where "practical activities function smoothly and transparently" (Benner, 1994, p. 73). In her research, it represented the embedded knowledge of clinical expertise in its everydayness (Benner, 1984/2001).

\section{Ethical considerations}

The ethical review board of the hospital where nurses were recruited approved this study (certificate No. FUM8038). This certificate was recognized by the ethical review board of the university. All participants (nursing students and nurses) provided written consent before their interview. To ensure confidentiality, a code and a fictitious name were firstly attached to each participant. In other words, real names are absent from sociodemographic questionnaires, transcripts, and primary investigator's (PI) journal. In order to avoid coercion in the recruitment of student participants, the PI did not teach undergraduate courses while the study took place.

\section{Setting}

The study was conducted in a French-Canadian university where its 3-year undergraduate nursing education program (2-year with an associate degree in nursing) leads to registration as a nurse. Graduates from this university were recruited from an affiliated French-speaking university hospital located on three geographical sites.

\section{Sample}

A convenience sample of nursing students ( $\mathrm{n}=18$ ) and nurses (n8) were recruited (Gray, Grove, \& Sutherland, 2017). For sampling criteria, all participants had to speak and understand French, and be interested in sharing their experiences pertaining to their own development of humanistic caring. Nursing students had to be studying in a specific competency-based approach program comprising a humanistic caring competency. They were recruited according to the number of academic years they had completed in the baccalaureate program:1) first year completed, 2) second year completed, and 3) reached the end of the third year.

Nurses had to hold a baccalaureate from the same competency-based approach program in which nursing students were enrolled. Nurses were recruited according to their expertise using some of Benner's (1984/2001) categories: 1) newly graduated (6-18 months of clinical practice), 2) experienced (2-4 years of clinical practice), and 3) accomplished (at least 5 years of clinical practice and be recognized as an "expert" by one peer). In order to facilitate the identification of this expertise, these accomplished nurses had to be "exemplary 
individuals ... who [were] really caring and [humanistic] in their interactions with patients" (Graber \& Mitcham, 2004, p. 88) or received praise from peers or patients for their humanistic nursing care. In this study, all accomplished nurses self-reported that they either received this praise directly from patients or their colleagues.

An invitation letter was sent to all eligible students via their academic email address. Also, the PI and a research assistant presented the study in few courses as a recruitment strategy. More recruitment strategies were deployed for nurses (see Table 1) because it took longer than expected to achieve a reasonable sample; that is, approximately 17 months. Sociodemographic characteristics of nursing students and nurses are summarized in Table 2.

\section{Data collection}

Data were collected through a semi-structured individual interview with each participant $(\mathrm{n}=26)$ from September 2015 to February 2017 (Munhall, 2012). The PI used an interviewing guide that had been elaborated through the lens of this study's disciplinary perspective (Cara et al., 2016) and previously validated by both his dissertation supervisors (JG and CC). Participants were asked questions such as: "What is the meaning of caring for a person with humanism?"; and "Tell me of an experience where you believe you have been humanistic with a person, a family, or a community." All interviews were recorded, lasting between 40 and $119 \mathrm{~min}$ (average: $63 \mathrm{~min}$ ). They were transcribed by an experienced typist and reread by the PI to ensure accuracy.

After 17 months, data collection was discontinued in spite of not achieving redundancy (Benner, 1994) in each of the six groups of participants. This decision was made in order to respect the academic deadlines for completing the PI's doctoral studies.

\section{Data analysis}

Verbatim transcripts were imported into the qualitative data analysis software ATLAS.ti 8. The analysis was adapted from Benner's (1994) phenomenological method, conceptualized in five iterative stages: 1) lines of inquiry, 2) central concerns and exemplars, 3) shared meanings, 4) final interpretations, and 5) dissemination of the interpretation (Crist \& Tanner, 2003). Individual analysis was mostly undergone throughout the first two stages, interparticipant analysis in the third stage, and intergroup analysis in the

Table 1: Intervention and recruitment strategies for nurses.

\begin{tabular}{ll}
\hline Timeline & Strategies \\
\hline October 2015 & $\begin{array}{l}\text { Presentation of the study to head nurses in one of the three geographical sites } \\
\text { of the hospital. } \\
\text { Presentation of the study to newly graduated and experienced nurses (less than } \\
\text { five years of clinical experience) at a conference. } \\
\text { Advertisement on the Facebook page of a continuation education committee that } \\
\text { was under the direction of the department of nursing. } \\
\text { Monthly reminders to head nurses by the hospital's resource person which worked } \\
\text { in the nursing research division. } \\
\text { October } 2015 \text { to June } 2016 \\
\text { November } 2015\end{array} \quad \begin{array}{l}\text { Opening of recruitment to the three geographical sites of the hospital. } \\
\text { Meeting with a head nurse and direct recruitment on a medical-surgical unit. } \\
\text { December } 2015\end{array}$ \\
April 2016 & Invitation through academic email of newly graduated nurses who had obtained their \\
beptember 2016 & baccalaureate in December 2015. \\
\hline
\end{tabular}


Table 2: Sociodemographic characteristics of participants $(n=26)$.

\begin{tabular}{|c|c|c|}
\hline Characteristics & Students $(n=18)$ & Nurses $(n=8)$ \\
\hline \multicolumn{3}{|l|}{ Advancement in program } \\
\hline First year of baccalaureate completed & 3 & - \\
\hline Second year of baccalaureate completed & 9 & \\
\hline Reached the end of the third year & 6 & \\
\hline \multicolumn{3}{|l|}{ Clinical experience } \\
\hline 6-18 months (newly graduated nurse) & - & 1 \\
\hline 2-4 years (experienced nurses) & - & 3 \\
\hline $5+$ years (accomplished nurses) & - & 4 \\
\hline \multicolumn{3}{|l|}{ Gender } \\
\hline Identified as female & 17 & 7 \\
\hline Identified as male & 1 & 1 \\
\hline \multicolumn{3}{|l|}{ Age } \\
\hline Mean age, years & 24 & 30 \\
\hline $20-29$ years old & 16 & 2 \\
\hline $30-39$ years old & 2 & 6 \\
\hline \multicolumn{3}{|l|}{ Ethnic background } \\
\hline Arabic or Middle Eastern & 1 & - \\
\hline Asian & 1 & - \\
\hline Black or African American & 1 & 1 \\
\hline Eastern European & 1 & - \\
\hline White & 14 & 7 \\
\hline \multicolumn{3}{|l|}{ Type of educational path in nursing } \\
\hline Associate degree in nursing to baccalaureate (2-year program) & 2 & 4 \\
\hline Baccalaureate in nursing (3-year program) & 16 & 4 \\
\hline
\end{tabular}

fourth stage. For the individual analysis (stages 1 and 2), the PI attempted, to understand participants' central concerns within their experiences by naming meaning units (Benner, Tanner, \& Chesla, 2009). These central concerns were summarized in a document in which exemplars were added and served as a basis to create a more interpretative summary. Exemplars are a salient verbatim representation of a similar or divergent dimension about participants' development (Benner, 1994). The first two individual analysis, central concerns summaries (including exemplars) and interpretative summaries were revised by one dissertation supervisor who is an expert in phenomenology, before proceeding. Then, the PI proceeded to interparticipant analysis, one group at a time, and uncovered shared meanings (stage 3 ) that were summarized in interpretative group summaries (Benner, 1994). In terms of interparticipant analysis, the PI read each summary (central concerns summary and individual interpretative summary), one participant of a given group at a time, in order to bring out emerging similarities pertaining to that specific group. Regarding intergroup analysis, the six interpretative group summaries (one per group) have been examined iteratively by the PI with the intention of identifying the learning differences between the groups. All six summaries were revised by the research team and interpretations were discussed and challenged.

\section{Findings}

Findings are presented within four dimensions: 1) role models and counterexamples, 2) exultation and trivialization of humanistic caring, 3) communication-related courses and patient storytelling, as well as 4) work overload. Because interviews were in French, all quotes in this paper were translated to English. 


\section{Learning from humanistic and caring role models or dehumanizing counterexamples}

The participants' experiences highlighted approaches of educators, nurse preceptors, and faculty members that were either congruent or incongruent with humanism and caring. When approaches were congruent, the development of humanistic caring appeared facilitated by role modeling. Incongruent approaches seemed to be either facilitating or hindering. Several participants were inspired by the way they were accompanied by their educators, identifying them as role models for their future nursing practice. These educators offered availability (i.e., to answer questions or listen to concerns), appeared to be authentically committed to their success, development, and in some cases, their well-being. The following statement, from Yunan, a secondyear student, is an exemplar:

"I admit I was highly influenced by the teacher who taught us a course. From my perspective, she was an example of caring. The way she behaved with us, her way of being as a person, it was as if she was caring [...]. Then she embodied it, when she spoke about humanism, the examples she had from her clinical practice or everything she had read about caring, it was as if she demonstrated it herself, in her attitude, and in what she said throughout the course."

Students felt inspired witnessing their nurse preceptors' acts of humanistic caring. A third-year student remembered her nurse preceptor showing interpersonal dexterity and ease in her commitment. This nurse preceptor was particularly good at putting patients at ease despite not knowing them extensively, in addition to finding "the right things" to say in delicate end-of-life situations, as illustrated by the following exemplar:

“Oh, I don’t know, she was just really humane, I think. But she was detached from the situations a little bit, but at the same time, she had a lot of compassion you know. She was very good at being 'detached but attached' [...]. She was like comfortable with patients, even though she didn't know them, [...] and she always knew what to say, "the right words", and I kind of admired her for that. [...] And I was like, maybe I too will become a good nurse one day." (Felicia, a third-year student)

However, several participants recognized that not all their nurse preceptors were role models. Nevertheless, in some instances, these dehumanizing counterexamples also engendered development, because it seemed to upset nursing students about a practice that they did not want to reproduce. An accomplished nurse divulged how one of her nurse preceptors did not encourage humanistic caring and that she promised herself not to become like this:

\footnotetext{
"I had a nurse preceptor who criticized me, and I have to say it shocked me. She told me I needed to be fast, to be faster and she even stated: ‘Okay, it's all nice to ask him how he's doing, but we know it alright? Now you're going to do your things'. [...] I was not even delaying anything, I was doing my dressing and talking [to the patient] at the same time, without making any mistakes. [...] I promised myself I would never become a nurse like this.” (Mihaela, an accomplished nurse)
}

Yet, several nursing students considered that their development had been impeded by their nurse preceptors. Numerous nursing students felt that there was little room for establishing a relationship with their patients and that it was more important to learn how to improve their dexterity and rapidity with technical procedures. A few nurse preceptors also gave nursing students the impression that they did not value humanistic caring. Additionally, in the academic setting, several nurse educators' ways of interacting with students were incongruent with the nursing school's humanistic framework: some sounded haughty and hierarchical; others allegedly failed to display concern and empathy while few appeared uninterested in their students. Few participants felt there was incongruence between these counterexamples and what was promoted in their curricula, as if what they observed and experienced did not match what they were encouraged to become. The following excerpt highlights this incongruence:

“The students' stress level was '+++'. I saw many students crying, I even cried myself at home because of the pressure [...]. When a student explained that our grades [...] didn't represent the workload and the effort put into our work, we were answered: 'I'm not here to assess the effort you put into your work'. It's true [...] it's not the effort and all that, but there's a way [to say it], it was completely devoid of empathy. And then after we were taught to 'care for the person with humanism', and we are like: 'Yeah, well nobody is listening to us'.” (Hallay, a second-year student) 


\section{Learning in environments in which humanistic caring is exalted or trivialized}

Development was supported in environments that gave importance to humanistic caring and was hindered when it was devalued. Several nursing students pinpointed that the omnipresence and the iteration of humanistic caring throughout their curriculum contributed to their development because it "was everywhere": the program's disciplinary perspective, the courses' contents, their assignments, as well as the assessment criteria. This following exemplar illustrates how this facilitated the development of humanistic caring:

"Well honestly, I would say it is the concept of caring that we keep on pointing out since we started [the baccalaureate]. [...] For us, I think that the concept of caring is a central aspect of everything we learn, everything we do, internships, even the theoretical parts, even when we learn in [problem-based learning], it's there. So just wagering on that from the beginning, I think it helped us to better predict what to expect in our internships and what patients should live in our presence." (Dencia, $a$ second-year student)

However, several nurses confessed that they dwelled in environments where they either received disheartening comments by their colleagues about humanistic caring or were compelled to reduce the amount of time given to their patients. For instance, an accomplished nurse remembered that, as a newly graduated nurse, she used to be reprimanded by senior nurses not appreciating how devoted she was to her patients:

"Yeah, jealousy. [...] At the beginning [of my clinical practice], it was like: 'Yeah, she’s the boss' favourite. We all know that this patient likes you, it's only because you do everything he wants'. But it wasn't about that, you know? So yeah, comments like this, [from] senior nurses, not the newly grads, it was from experienced nurses. Not many, but one or two who verbally assaulted me." (Mihaela, an accomplished nurse)

Another accomplished nurse experienced a similar pattern with her colleagues and her head nurse where she felt pressurized to decrease the intensity of interactions with her patients:

“Yeah, I was reprimanded, sometimes they [nurses] even told me: 'If you're not taking your break, others will be delayed'. A social-like pressure, and I responded: 'No it's okay, I remain available on the ward'. I even met a head nurse for this reason, and I had to explain that it was the kind of nursing care I wanted to provide, but she considered that I was 'chitchatting' a lot." (Pavlina, an accomplished nurse)

\section{Learning from communication-related courses and patient storytelling}

Most student participants associated nurse-patient communication to humanistic caring and it may be why courses focusing on this dimension were perceived as contributions to their development. According to participants, such courses were specific to mental health, palliative care, family systems, and communication workshops. For instance, Shélanie witnessed the therapeutic added value of care-related communication skills to the family in a course:

"For me, the course that has struck me the most [...] is the [one related to family systems approach]. Well, I was doing interventions without realizing that it was really a therapeutic intervention, nor did I realize that by asking a specific question, it would allow me to explore [the family's] strengths. I became more aware of communication skills, circular questioning, and I adopted a more systemic vision in front of a group of people, with family members.” (Shélanie, a third-year student)

Several nursing students stated learning from patients who were invited to tell their stories in the classroom while few others recommended increasing the amount of patient storytelling in the curriculum. Participants agreed that this pedagogical strategy contributed to their development because it made them realize that they could "make a difference" for patients in terms of transforming the ways in which health experiences are lived, as stated by Laurence, a first-year student:

"She [the patient] said how she used to be around nurses, and just being there and listening was what really changed her experience for her. So, even if for us [nursing students] we say that it is insignificant [...] to hear it from the perspective of a 
patient [...], it allowed me to realize, 'yeah, even a seemingly trivial gesture such as listening to the person can change their experience or how they live the situation

\section{Learning to cope with work overload}

Work overload was a salient hindering aspect acknowledged by at least one participant in each group. Several students mentioned that they were able to embrace humanistic caring because of their lighter workload as students or nursing externs. Some of them, mostly third-year students, feared that they would not be able to sustain such a practice after their graduation. A newly graduated nurse repeatedly mentioned that she felt torn between her humanistic and caring ideals and what she was able to put into practice, explicitly because of work overload. Most experienced and accomplished nurses conceded that there were instances where it was a serious issue. In the following exemplar, Pavlina, an accomplished nurse explains how care safety was compromised in a nursing home where she practiced:

"You know, every minute was counted, but like, you were there for your technical skills. It's okay, you know, I'm comfortable with that [technical skills], but that evening, administering medication was like working on an assembly line factory. I could not fulfil everything, even when I was giving medication, I was asking myself: 'I think I need to assess the apical pulse, do I have time to do it?' It was bad to the point that I was 'prioritizing my priorities'. And that evening, I did not offer humanistic care."

However, the importance given to work overload tended to fade over time as nurses gained clinical experience. Experienced and accomplished nurses highlighted that their acquired expertise allowed them to be more efficient with time management, which in turn gave them the feeling of having "more time" as compared to when they were newly graduated nurses, as underscored in the following excerpt:

"At one point I became [humanistic and caring] again because, for example when you work, you become more comfortable, you understand your role, what your job is, you know what needs to be delegated [to a nursing assistant], what you have to monitor." (Kim, an experienced nurse)

\section{Discussion}

The findings drew attention to the pivotal role played by all nurse educators including the clinical nurse preceptors in contact with nursing students while developing humanistic caring. Research participants expressed that the nurse educators' approach could promote, or limit, their development. As obvious as it might appear, the development was fostered when educators and nurse preceptors were acting in ways congruent with how they encouraged students to be with their patients; in other words, to represent humanistic and caring role models with whom students could identify. This finding appears consistent with the results of numerous studies published in the past 20 years (Beck, 2001; Bray et al., 2014; Jack, Hamshire, \& Chambers, 2017; Kosowski, 1995). However, what stands out as innovative in the present study is that this finding (nurse educators as role models) was emphasized longitudinally in each group of participants.

On the contrary, participants who observed an incongruence between humanistic caring and the educators' or preceptors' approach felt that their development was inhibited. The only instance in which a dehumanizing and an uncaring approach remained conducive to the development of students' humanistic caring concerned the observation of interactions between preceptors and patients. This specific way of learning was labeled as "reversing" in the Kosowski's (1995) critical phenomenological study. Indeed, nursing students positively "reversed" the dehumanizing and uncaring observed behaviors of their nurse preceptors and made "a 'firm commitment' never to behave in the same 'uncaring' manner toward patients in the future" (Kosowski, 1995, p. 238). However, it was not the case for every participant in the present study. 
This divergence was also obtained in the qualitative descriptive study conducted by Ma, Li, Liang, Bai, and Song (2014) in China. In fact, Ma et al. (2014) acknowledged that it was often uncaring encounters with nursing preceptors that would shock students the most and generate a reflection about caring (hence their development), but that an unbearable number of these encounters could be unfavorable by causing apathy and moral distress. These impacts were also evoked by Canadian nursing students (Engel, Salfi, Micsinszki, \& Bodnar, 2017) who recognized dehumanizing and unethical practices by their nursing preceptors. Even though these practices were incongruous with what they were taught ("the ought"), several participants rationalized their inaction because of anticipation and fear of retribution (Engel et al., 2017). All too often, students act with passivity when witnessing poor practice because of their "low status" in the "healthcare hierarchy", as also outlined in the survey of Rees, Monrouxe, and McDonald (2015). The findings of this current study showed that several students practiced incongruently with their humanistic and caring ideals in their internships because they feared academic failure. This emphasizes the persuasiveness of nurse preceptors regarding the development of humanistic caring.

The omnipresence of humanistic caring repeatedly emphasized over the course of a baccalaureate program was perceived as having positive impacts on students' development. These findings are akin to the literature (Drumm \& Chase, 2010; Krol, 2010), which underlined that the continuous exposure to caring in various pedagogical activities, for instance assignments in both academic and clinical settings, helped students become aware that it was intended for their future practice. Thereby, it seems that the development of students' humanistic caring was not only driven by its omnipresence in the curriculum, but also because it was expected and assessed. It is perhaps the first time that a study specifically highlighted the link between the development of humanistic caring and its assessment in a curriculum.

In regards to the curriculum, there was a diversity of experiences involving courses or pedagogical activities that were specifically beneficial to the development of students' humanistic caring. When taken from a broader perspective, most of these experiences featured nurse-patient communication. Even if communication alone might not grasp the wide-ranging meanings of humanistic caring, it might, however, be an expression of its embodiment given the appropriate attitudes (Cara et al., 2016). However, to the knowledge of the present authors, no studies were found in the literature about nurse-patient communication training in the context of developing students' humanistic caring.

Patient storytelling seemed to bring a distinct awareness about the importance and benefits of humanistic caring. this finding is in agreement with the results of the meta-narrative review of Rose et al. (2016), who asserted that patient storytelling could cultivate humanism in healthcare because of its perceived authenticity (i.e., "real") and its sense-making potential. Again, this is congruent with the participants' experiences as they explicitly referred to the awareness that was raised by patient storytelling. Participants were more aware of the potential benefits of humanistic caring for patients and the added value of "the little things" that hold significance to them.

As for hindering environments involving colleagues and managers that either pressurized participants or trivialized humanistic caring, the results are comparable to previous studies involving nurses (Cara, 1999; Christiansen, O’Brien, Kirton, Zubairu, \& Bray, 2015; Jones, Winch, Strube, Mitchel, \& Henderson, 2016). For instance, the qualitative exploratory study of Jones et al. (2016) revealed that nurses working in the intensive care unit perceived that their compassion was inhibited by "difficult work associates" and the lack of acknowledgment related to compassionate care as it was not seen as real work.

Lastly, work overload and the lack of time that resulted were perceived as a restraining aspect against humanization of care and this is mirrored in previous research (Chen et al., 2017; Christiansen et al., 2015; Hunter, McCallum, \& Howes, 2018). For instance, British nursing students who were interviewed by Curtis et al. (2012, p. 792) "expressed that having time to communicate with patients was central to emphasizing and therefore compassionate practice". In the present study, several nursing students feared losing touch with humanistic caring after their graduation because of work overload and this is reminiscent of a former grounded theory study (Pearcey \& Draper, 2008). Indeed, several of these first-year students expressed their concerns about the possibility of remaining caring practitioners despite the number of technical procedures to be completed and the speed at which they are supposed to be performed. In the present study, however, the 
perceptions associated with work overload tended to evolve through the acquisition of clinical expertise: the more experience nurses acquired, the less hindered by the work overload they appeared. This finding was certainly made possible because of the longitudinal documentation of humanistic caring. It is also supported by the results of a qualitative study (Åström, Norberg, \& Hallberg, 1995) in which skilled and experienced Swedish nurses proclaimed that they needed from 1 to 3 years of practice before they could recede from routines and technical procedures, and therefore lean toward caring. In the current study, the experienced and accomplished nurses perceived that the clinical experience they had acquired allowed them to manage time more efficiently, which seemed to soften the role played by the work overload on their development of humanistic caring.

\section{Limitations}

It is important to point out some limitations. A first limitation stems from the fact that there were more students $(n=18)$ who participated in the study as compared to nurses $(n=8)$, in addition to gathering the experience of only one newly graduated nurse. It would have been valuable to integrate the perceptions of a greater number of nurses to ensure redundancy (Benner, 1994) in each group. However, it was not possible despite the multiple recruitment strategies and incentives used. A second limitation arises because of the rather specific sampling criteria that were used, which could impair the transferability of the findings (Lincoln \& Guba, 1985). Indeed, the findings reflect the development of participants who studied in a setting where humanistic caring is at the cornerstone of its baccalaureate program (Cara et al., 2016). It is plausible that some dimensions pertaining to the development of humanistic caring, its omnipresence in a curriculum among other things, might have been overemphasized because of the above-stated reason. A third limitation, a strong contextualization of the findings, results from recruiting students and graduates of the same undergraduate nursing education program. In return, this methodological choice contributed to ensure a certain amount of congruence within the study and to recognize the learning trajectory of participants that had gone through comparable training.

\section{Conclusion}

The findings of this study emphasized that the work overload is particularly frightening for nursing students who are close to graduation, and that it is disheartening and challenging for newly graduated nurses to keep humanism and caring in their practice. It might be appropriate to engage in a dialog with nursing students about the "reality" of contemporary nursing practice and the paradoxical gap with their ideals. This dialog could raise their awareness about the upcoming challenges of the clinical settings as well as the strategies to overcome them, potentially alleviating the disenchantment caused by the aforementioned gap. Moreover, it is imperative to prepare students becoming change agents so that they can, one day, successfully challenge the status quo in the clinical settings. However, the authors are confident that an equilibrium must reside between this preparation and the ideals of practice conveyed by nursing education: the higher the expectations are, the better prepared students must be. The authors also recognize that newly graduated nurses have a personal responsibility for keeping their ideals in nursing despite the clinical difficulties. As a way to soften the fairly considerable gap between the workload of a third-year nursing student and the one of a newly graduated nurse (only couple months apart), these authors encourage educators to gradually bring students to take responsibility for an almost full assignment. Clinical settings are also invited to give a more progressive workload to newly graduated nurses. In doing so, nursing students will most likely be better prepared to cope with the challenges of the clinical settings and be less disenchanted with their inability to practice in harmony with their humanistic and caring ideals.

In terms of implications for further nursing research, the findings reinforce the need to re-study the impacts of improved orientation programs intended for newly graduated nurses. There are numerous publications (Abiodun, Daniels, Pimmer, \& Chipps, 2019; Ke, Kuo, \& Hung, 2017; Lindfors, Meretoja, Kaunonen, \& 
Paavilainen, 2018; Pasila, Elo, \& Kääriäinen, 2017) that synthesize and clarify the needs of newly graduated nurses in terms of orientation programs and their benefits. Using these findings, it would be possible to develop an orientation program taking into account the specific learning needs of newly graduated nurses and then assess the impacts of this program on different parameters pertaining to humanistic caring.

Moreover, the findings revealed that it is helpful but insufficient to iterate and focus on humanistic caring through undergraduate education. Indeed, its development can be, to a certain degree, reversed by dehumanizing educators, nurse preceptors, and managers, who reinforce the idea that positive role models and relationships are desirable in order to become a humanistic and caring practitioner. The present authors wish to raise awareness among all educators about the opportunity and the persuasiveness they possess in promoting nursing students' and nurses' humanistic caring. Educators are encouraged to display a collaborative and a close-to-egalitarian attitude with nursing students (Hills \& Watson, 2011), genuinely. As asserted by a former humanist (Rogers \& Lyon, 2014, p. 188), "if you care for [your students] as persons, they will return that caring. If you can understand their feelings, it will expand and blossom and bloom.”

Acknowledgments: They thank all participants for their involvement in this doctoral research. The first author received doctoral scholarships from the Ministère de l'Éducation et de l'Enseignement supérieur (MEES) in Quebec; the Fonds de recherche du Québec - Société et culture (FRQ-SC); the Faculty of Nursing of the Université de Montréal; the Department of Nursing of the Jewish General Hospital, in Montreal; the Équipe FUTUR, funded by the FRQ-SC; and the Faculty of Graduate and Postdoctoral Studies of the Universite de Montréal.

Research funding: The first author received doctoral scholarships from the Ministère de l'Éducation et de l'Enseignement supérieur (MEES) in Quebec; the Fonds de recherche du Québec - Société et culture (FRQ-SC), under Grant 192404; the Faculty of Nursing of the Universite de Montréal; the Department of Nursing of the Jewish General Hospital, in Montreal; the Équipe FUTUR, funded by the FRQ-SC; and the Faculty of Graduate and Postdoctoral Studies of the Université de Montréal.

Author contribution: All the authors have accepted responsibility for the entire content of this submitted manuscript and approved submission.

Conflicts of Interest: The authors disclose the absence of conflicts of interest.

Informed consent: Informed consent was obtained from all individuals included in this study.

Ethical approval: The ethical review board of the hospital where nurses were recruited approved this study (certificate No. FUM-8038). This certificate was recognized by the ethical review board of the university.

\section{References}

Abiodun, R. O., Daniels, F., Pimmer, C., \& Chipps, J. (2019). Nurse graduates' experiences and support needs: A qualitative systematic review of South Africa's community service programme. Curationis, 42(1), 1-12.

Adam, D., \& Taylor, R. (2014). Compassionate care: Empowering students through nurse education. Nurse Education Today, 34 , 1242-1245.

American Nurses Association (2015). Nursing: Scope and standards of practice (3rd ed.). Silver Spring, MD: Author.

Åström, G., Norberg, A., \& Hallberg, I. R. (1995). Skilled nurses' experiences of caring. Journal of Professional Nursing, 11, 110-118. Avoine, M.-P. (2012). La signification de pratiques déshumanisantes telles que vécues par des patients hospitalisés ou ayant été hospitalisés en centre de réadaptation [The meaning of dehumanizing practices as experienced by hospitalized or previously hospitalized patients in a rehabilitation center] [Masters' thesis]. ProQuest Dissertations \& Theses Global. Available from (UMI No. MR96229).

Beagan, B., \& Ells, C. (2007). Values that matter, barriers that interfere: The struggle of Canadian nurses to enact their values. Canadian Journal of Nursing Research, 39(4), 36-57. Retrieved from http://www.ingentaconnect.com/.

Beck, C. T. (2001). Caring within nursing education: A metasynthesis. Journal of Nursing Education, 40, 101-109.

Benner, P. (1994). Interpretive phenomenology: Embodiment, caring, and ethics in health and illness. Thousand Oaks, CA: SAGE.

Benner, P. (2001). From novice to expert: Excellence and power in clinical nursing practice. Upper Saddle River, NJ: Prentice Hall. Original work published 1984. 
Benner, P., Tanner, C., \& Chesla, C. (2009). Expertise in nursing practice: Caring, clinical judgment, and ethics (2nd ed.). New York, NY: Springer Publishing Company.

Berglund, M., Westin, L., Svanström, R., \& Sundler, A. J. (2012). Suffering caused by care-patients' experiences from hospital settings. International Journal of Qualitative Studies on Health and Well-Being, 7, 1-9.

Boykin, A., Schoenhofer, S. 0., \& Aleman, D. (2003). Transforming practice using a caring-based nursing model. Nursing Administration Quarterly, 27, 223-230. Retrieved from http://journals.lww.com/naqjournal/pages/default.aspx.

Bray, L., O’Brien, M. R., Kirton, J., Zubairu, K., \& Christiansen, A. (2014). The role of professional education in developing compassionate practitioners: A mixed methods study exploring the perceptions of health professionals and pre-registrations students. Nurse Education Today, 34, 480-486.

Brown, J., Nolan, M., \& Davies, S. (2008). Bringing caring and competence into focus in gerontological nursing: A longitudinal, multi-method study. International Journal of Nursing Studies, 45, 654-667.

Buber, M. (1996). I and thou. A new translation, with a prologue and notes by Walter Kaufmann (W. Kaufmann, Trans.). New York, NY: Touchstone. Original work published 1970.

Cara, C. (1999). A relational caring inquiry: Nurses' perspective on how management can promote a caring practice. International Journal for Human Caring, 3(1), 22-30.

Cara, C. (2001). The apprenticeship of caring. International Journal for Human Caring, 5(2), 33-41.

Cara, C., Gauvin-Lepage, J., Lefebvre, H., Létourneau, D., Alderson, M., Larue, C., \& Mathieu, C. (2016). Le Modèle humaniste des soins infirmiers - UdeM: Perspective novatrice et pragmatique [The Humanistic Model of Nursing Care - UdeM: An innovative and pragmatic perspective]. Recherche en soins infirmiers, 125, 20-31.

Chen, C. S., Chan, S. W.-C., Chan, M. F., Yap, S. F., Wang, W., \& Kowitlawakul, Y. (2017). Nurses' perceptions of psychosocial care and barriers to its provision: A qualitative study. Journal of Nursing Research, 25(6), 411-418.

Christiansen, A., O’Brien, M. R., Kirton, J. A., Zubairu, K., \& Bray, L. (2015). Delivering compassionate care: The enablers and barriers. British Journal of Nursing, 24, 833-837.

Copson, A., \& Grayling, A. C. (2015). The Wiley Blackwell handbook of humanism. Chichester, United Kingdom: Wiley Blackwell.

Cornwell, J., Donaldson, J., \& Smith, P. (2014). Nurse education today: Special issue on compassionate care. Nurse Education Today, 34, 1188-1189.

Crist, J. D., \& Tanner, C. A. (2003). Interpretation/analysis methods in hermeneutic interpretive phenomenology. Nursing Research, 52, 202-205. Retrieved from http://journals.Iww.com/nursingresearchonline/pages/default.aspx.

Curtis, K., Horton, K., \& Smith, P. (2012). Student nurse socialisation in compassionate practice: A grounded theory study. Nurse Education Today, 32, 790-795.

Davies, T. (2008). Humanism (2nd ed.). New York, NY: Routledge.

Delmas, P., O’Reilly, L., Iglesias, K., Cara, C., \& Burnier, M. (2016). Feasibility, acceptability, and preliminary effects of educational intervention to strengthen humanistic practice among hemodialysis nurses in the Canton of Vaud, Switzerland: A pilot study. International Journal for Human Caring, 20, 31-43.

Dewar, B., \& Cook, F. (2014). Developing compassion through a relationship centred appreciative leadership programme. Nurse Education Today, 34, 1258-1264.

Dewar, B., \& Nolan, M. (2013). Caring about caring: Developing a model to implement compassionate relationship centred care in an older people case setting. International Journal of Nursing Studies, 50, 1247-1258.

Dingman, S. K., Williams, M., Fosbinder, D., \& Warnick, M. (1999). Implementing a caring model to improve patient satisfaction. Journal of Nursing Administration, 29, 30-37. Retrieved from http://journals.lww.com/jonajournal/Pages/default.aspx.

Drumm, J., \& Chase, S. K. (2010). Learning caring: The student's experience. International Journal for Human Caring, $14(4), 31-37$.

Eliasson, M., Kainz, G., \& von Post, I. (2008). Uncaring midwives. Nursing Ethics, 14, 500-511.

Engel, J., Salfi, J., Micsinszki, S., \& Bodnar, A. (2017). Informed strangers: Witnessing and responding to unethical care as student nurses. Global Qualitative Nursing Research, 4, 1-9.

Goudreau, J., Boyer, L., \& Létourneau, D. (2014). Clinical reasoning in nursing practice: A cognitive learning model based on a think aloud methodology. Advancement in Nursing Education - Avancées en formation infirmière, 1(1), 1-18.

Graber, D. R., \& Mitcham, M. D. (2004). Compassionate clinicians: Take patient care beyond the ordinary. Holistic Nursing Practice, 18, 87-94. Retrieved from http://journals.lww.com/hnpjournal/pages/default.aspx.

Gray, B. (2009). The emotional labour of nursing - defining and managing emotions in nursing work. Nurse Education Today, 29, 168-175.

Gray, J. R., Grove, S. K., \& Sutherland, S. (2017). Burns and Grove's The practice of nursing research: Appraisal, synthesis, and generation of evidence (8th ed.). Saint-Louis, MO: Elsevier.

Halldórsdóttir, S. (2008). The dynamics of the nurse-patient relationship: Introduction of a synthesized theory from the patient's perspective. Scandinavian Journal of Caring Sciences, 22, 643-652.

Halldórsdóttir, S., \& Karlsdóttir, S. I. (1996). Empowerment or discouragement: Women's experience of caring and uncaring encounters during childbirth. Health Care for Women International, 17, 361-379.

Haugan, G., Innstrand, S. T., \& Moksnes, U. K. (2013). The effect of nurse-patient interaction on anxiety and depression in cognitively intact nursing home patients. Journal of Clinical Nursing, 22, 2192-2205. 
Heidegger, M. (2008). Being and time (J. Macquarrie \& E. Robinson, Trans) (2nd ed.). New York, NY: HarperCollins. (Original work published 1927).

Hills, M., \& Watson, J. (2011). Creating a caring science curriculum: An emancipatory pedagogy for nursing. New York, NY: Springer Publishing Company.

Hunter, D., McCallum, J., \& Howes, D. (2018). Compassion in emergency departments. Part 2: Barriers to the provision of compassionate care. Emergency Nurse, 26(3), 28-33.

Husserl, E. (1950). Idées directrices pour une phénoménologie [Ideas for pure phenomenology and phenomenological philosophy] (P. Ricoeur, Trans.). Paris, France: Gallimard. (Original work published 1913).

Jack, K., Hamshire, C., \& Chambers, A (2017). The influence of role models in undergraduate nurse education. Journal of Clinical Nursing, 26, 4707-4715.

Jones, J., Winch, S., Strube, P., Mitchel, M., \& Henderson, A. (2016). Delivering compassionate care in intensive care units: Nurses' perceptions of enablers and barriers. Journal of Advanced Nursing, 72, 3137-3146.

Karlsson, M., Bergbom, I., von Post, I., \& Berg-Nordenberg, L. (2004). Patient experiences when the nurse cares for and does not care for. International Journal for Human Caring, 8(3), 30-36.

Ke, Y. T., Kuo, C. C., \& Hung, C. H. (2017). The effects of nursing preceptorship on new nurses' competence, professional socialization, job satisfaction and retention: A systematic review. Journal of Advanced Nursing, 73, 2296-2305.

Kosowski, M. M. R. (1995). Clinical learning experiences and professional nurse caring: A critical phenomenological study of female baccalaureate nursing students. Journal of Nursing Education, 34, 235-242.

Krol, P. (2010). L'apprentissage du caring chez les étudiantes infirmières au baccalauréat dans un programme de formation par compétences [The learning of caring of undergraduate nursing students in a competency-based baccalaureate]. Recherche en soins infirmiers, 102, 59-72. Retrieved from http://fulltext.bdsp.ehesp.fr/Rsi/102/59.pdf.

Lamont, C. (1997). The philosophy of humanism. Amherst, NY: Humanist Press.

Larson, L. (2004). Restoring the relationship: The key to nurse and patient satisfaction. Trustee, 57(9), 21-24. Retrieved from http:// www.trusteemag.com/.

Lee-Hsieh, J., Kuo, C.-L., Turton, M. A., Hsu, C.-L., \& Chu, H.-C. (2007). Action research on the development of a caring curriculum in Taiwan: Part II. Journal of Nursing Education, 46, 553-561. Retrieved from http://www.healio.com/journals/JNE.

Létourneau, D., Cara, C., \& Goudreau, J. (2016). Agir avec humanisme : l'approche humaine et relationnelle du soin, un pouvoir de l'infirmière [Caring for the person with humanism: The humane and relational approach to care, a power of the nurse]. Perspective infirmière, 13(5), 32-34. Retrieved from https://www.oiiq.org/sites/default/files/uploads/periodiques/ Perspective/vol13no5/10-formation.pdf.

Létourneau, D., Cara, C., \& Goudreau, J. (2017). Humanizing nursing care: An analysis of caring theories through the lens of humanism. International Journal for Human Caring, 21, 32-40.

Létourneau, D., Goudreau, J., \& Cara, C. (2020). Humanistic caring, a nursing competency: Modelling a metamorphosis from students to accomplished nurses. Scandinavian Journal of Caring Sciences https://doi.org/10.1111/scs.12834.

Lincoln, Y. S., \& Guba, E. G. (1985). Naturalistic inquiry. London, United Kingdom: SAGE.

Lindfors, K., Meretoja, R., Kaunonen, M., \& Paavilainen, E. (2018). Preceptors' perceptions of the elements of a successful and an unsuccessful orientation period for newly graduated nurses. Journal of Nursing Management, 26, 256-262.

Logan, K. A. (2017). Meta-synthesis of caring within nursing education (Doctoral dissertation) ProQuest Dissertations \& Theses Global. Available from (UMI No. 10260852).

Ma, F., Li, J., Zhu, D., Bai, Y., \& Song, J. (2013). Confronting the caring crisis in clinical practice. Medical Education, 47, $1037-1047$.

Ma, F., Li, J., Liang, H., Bai, Y., \& Song, J. (2014). Baccalaureate nursing students' perspectives on learning about caring in China: A qualitative descriptive study. BMC Medical Education, 14(42), 1-9.

Maben, J., Latter, S., \& Clark, J. M. (2007). The sustainability of ideals, values and the nursing mandate: Evidence from a longitudinal qualitative study. Nursing Inquiry, 14, 99-113.

Mayeroff, M. (1990). On caring. New York, NY: HarperPerennial. Original work published 1971.

Mazzocco, A. (2006). Interpretations of Renaissance humanism. Leiden, Netherlands: Brill.

McClelland, L. E., Gabriel, A. S., \& DePuccio, M. J. (2018). Compassion practices, nurse well-being, and ambulatory patient experience ratings. Medical Care, 56, 4-10.

Mikkonen, K., Kyngäs, H., \& Kääriäinen, M. (2015). Nursing students' experiences of the empathy of their teachers: A qualitative study. Advances in Health Sciences Education, 20, 669-682.

Munhall, P. L. (2012). Nursing research: A qualitative perspective (5th ed.). Sudbury, MA: Jones \& Bartlett Learning.

O'Reilly, L., Cara, C., Avoine, M.-P., \& Brousseau, S. (2011). Résilience : pour voir autrement l'intervention en réadaptation [Resiliency: To see the rehabilitation intervention differently]. Revue Développement humain, handicap et changement social, 19(1), 111-116. Retrieved from http://ripph.qc.ca/sites/default/files/19-01-2011-15.pdf.

Palese, A., Tomietto, M., Suhonen, R., Efstathiou, G., Tsangari, H., Merkouris, A., \& Papastavrou, E. (2011). Surgical patient satisfaction as an outcome of nurses' caring behaviors: A descriptive and correlational study in six European countries. Journal of Nursing Scholarship, 43, 341-350.

Pasila, K., Elo, S., \& Kääriäinen, M. (2017). Newly graduated nurses' orientation experiences: A systematic review of qualitative studies. International Journal of Nursing Studies, 70, 7-27. 
Pearcey, P. (2010). 'Caring? It’s the little things we are not supposed to do anymore'. International Journal of Nursing Practice, 16, 51-56.

Pearcey, P., \& Draper, P. (2008). Exploring clinical nursing experiences: Listening to student nurses. Nurse Education Today, 28, 595-601.

Raines, D. A. (2007). Caring abilities of students in an accelerated program of study: A program evaluation study. International Journal for Human Caring, 11(3), 45-49.

Rees, C. E., Monrouxe, L. V., \& McDonald, L. A. (2015). 'My mentor kicked a dying woman's bed...' Analysing UK nursing students' 'most memorable' professionalism dilemmas. Journal of Advanced Nursing, 71, 169-180.

Rogers, C. R. (1961). On becoming a person: A therapist's view of psychotherapy. Boston, MA: Houghton Mifflin Company.

Rogers, C. R. (2012). On becoming a person: A therapist's view of psychotherapy. New York, NY: Houghton Mifflin Company. Original work published 1995.

Rogers, C. R., \& Lyon, H. C. (2014). A final dialogue. In C. R. Rogers, H. C. Lyon, \& R. Tausch (Eds.), On becoming an effective teacher: Person-centered teaching, psychology, philosophy, and dialogues with Carl R. Rogers and Harold Lyon (pp. 179-192). Abingdon, United Kingdom: Routledge.

Rose, R., Chakraborty, S., Mason-Lai, P., Brocke, W., Page, S. A., \& Cawthorpe, D. (2016). The storied mind: A meta-narrative review exploring the capacity of stories to foster humanism in health care. Journal of Hospital Administration, 5(1), 52-61.

Rytterstöm, P., Cedersund, E., \& Arman, M. (2009). Care and caring culture as experienced by nurses working in different care environments: A phenomenological-hermeneutic study. International Journal of Nursing Studies, 46, 689-698.

Smith, M. J., \& Liehr, P. R. (2014). Understanding middle range theory by moving up and down the ladder of abstraction. In M. J. Smith, \& P. R. Liehr (Eds.), Middle range theory for nursing (3rd ed.) (pp. 15-34). New York, NY: Springer Publishing Company.

Spiegelberg, H., \& Schuhmann, K. (1994). The phenomenological movement: A historical introduction. Dordrecht, Netherlands: Kluwer Academic.

St-Germain, D., Blais, R., \& Cara, C. (2008 December). La contribution de l'approche de caring des infirmières à la sécurité des patients en réadaptation : Une étude novatrice [The contribution of the nurses' caring approach to patients' satefy in rehabilitation: An innovative study]. Recherche en soins infirmiers, 95, 57-69. Retrieved from http://fulltext.bdsp.ehesp.fr/ Rsi/95/57.pdf.

Svanström, R., Sundler, A. J., Berglund, M., \& Westin, L. (2013). Suffering caused by care-elderly patients' experiences in community care. International Journal of Qualitative Studies on Health and Well-Being, 8, 1-10.

Tardif, J. (2006). L'évaluation des compétences. Documenter le parcours de développement [The assessment of competencies. Documenting the developmental path]. Montreal, Quebec: Chenelière Éducation.

Tektaş, P., \& Çam, O. (2017). The effects of nursing care based on Watson's theory of Human Caring on the mental health of pregnant woman after a pregnancy loss. Archives of Psychiatric Nursing, 31, 440-446.

van der Cingel, M. (2011). Compassion in care: A qualitative study of older people with a chronic disease and nurses. Nursing Ethics, $18,672-685$.

Wiechula, R., T.Conroy, A. L.Kitson, R. J.Marshall, N.Whitaker, \& P.Rasmussen (2016) Umbrella review of the evidence: What factors influence the caring relationship between a nurse and patient?. Journal of Advanced Nursing, 72, 723-734.

Wolf, Z. R. (2012). Nursing practice breakdowns: Good and bad nursing. Medsurg Nursing, 21(36), 16-22. Retrieved from http:// www.medsurgnursing.net/cgi-bin/WebObjects/MSNJournal.woa.

Wolf, Z. R., Byrne, D., \& Hanson-Zalot, M. (2018). Undergraduate nursing students' caring behaviors: A cross-sectional study. International Journal for Human Caring, 22, 199-208. 